\title{
Corrigendum: Gain control of gamma frequency activation by a novel feed forward disinhibitory loop: implications for normal and epileptic neural activity
}

\author{
Zeinab Birjandian, Chakravarthi Narla and Michael O. Poulter * \\ Molecular Medicine Research Group, Department of Physiology and Pharmacology, Robarts Research Institute, The University of Western Ontario, \\ London, ON, Canada \\ *Correspondence: mpoulter@robarts.ca
}

Edited and reviewed by:

Luis De Lecea, Stanford University, USA

Keywords: epilepsy, disinhibition, interneuron, endopiriform cortex, olfactory cortex, piriform cortex

\section{A corrigendum on}

Gain control of gamma frequency activation by a novel feed forward disinhibitory loop: implications for normal and epileptic neural activity

by Birjandian, Z., Narla, C., and Poulter, $M$. O. (2013). Front. Neural Circuits 7:183. doi: 10.3389/fncir.2013.00183

Figure 1 of the article by Birjandian et al. (2013) contained a minor error in the legend, which we hereby rectify. In the original figure legend panel $(\mathbf{C})$ is described as two examples of whole cell patch recordings made from layer II and layer III neurons. But in fact panel (C) correspond to normalized change in $\Delta \mathrm{F} / \mathrm{F}$ vs. stimulus intensity from 8 recordings in the layer II. Panels (D,E) correspond to normalized change in $\Delta \mathrm{F} / \mathrm{F}$ vs. stimulus intensity from 8 recordings in DEn and Layer III but not layer II. We therefore would like to make a correction to Figures 1C-E.

\section{REFERENCE}

Birjandian, Z., Narla, C., and Poulter, M. O. (2013). Gain control of gamma frequency activation by a novel feed forward disinhibitory loop: implications for normal and epileptic neural activity. Front. Neural Circuits 7:183. doi: 10.3389/fncir.2013.00183

Conflict of Interest Statement: The authors declare that the research was conducted in the absence of any commercial or financial relationships that could be construed as a potential conflict of interest.

Received: 03 June 2014; accepted: 11 June 2014; published online: 21 August 2014.

Citation: Birjandian Z, Narla C and Poulter MO (2014) Corrigendum: Gain control of gamma frequency activation by a novel feed forward disinhibitory loop: implications for normal and epileptic neural activity. Front. Neural Circuits 8:70. doi: 10.3389/fncir.2014.00070

This article was submitted to the journal Frontiers in Neural Circuits.

Copyright (c) 2014 Birjandian, Narla and Poulter. This is an open-access article distributed under the terms of the Creative Commons Attribution License (CC BY).

The use, distribution or reproduction in other forums is permitted, provided the original author(s) or licensor are credited and that the original publication in this journal is cited, in accordance with accepted academic practice. No use, distribution or reproduction is permitted which does not comply with these terms. 